
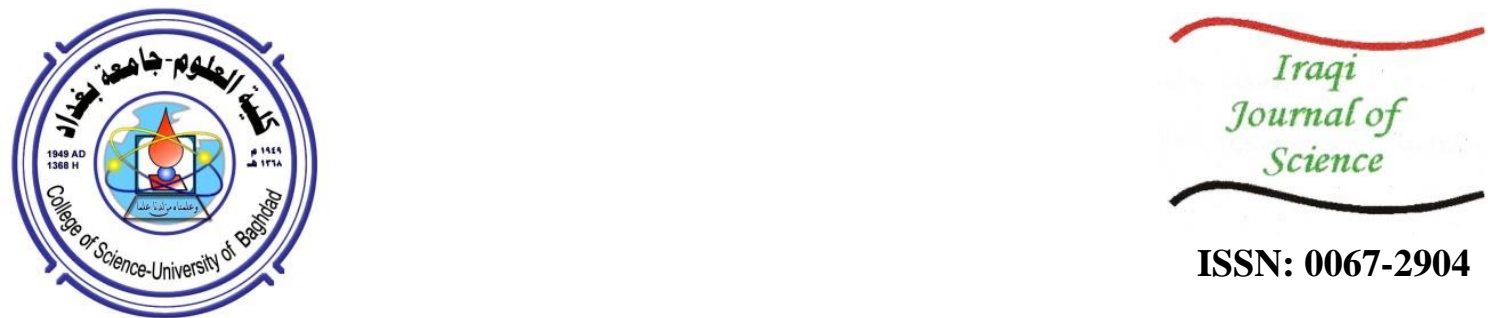

ISSN: 0067-2904

\title{
Evaluation of Serum Clusterin Levels in Type 2 Diabetic Men with and without Cardiovascular Disease
}

\author{
Safa S. Fayez ${ }^{1 *}$, Rashied. M. Rashied ${ }^{1}$, Shakir F.T. Al-Alaaraji ${ }^{2}$ \\ ${ }^{1}$ Department of Biology, College of Sciences, University Of Anbar, Ramadi, Iraq \\ ${ }^{2}$ Department of Chemistry, College of Education for Pure Sciences, University Of Anbar, Ramadi, Iraq
}

Received: 13/9/ 2019

Accepted: 31/10/2019

\begin{abstract}
Objectives: The objective of this study was to evaluate serum levels of clusterin (CLU) in type 2 diabetics with and without cardiovascular disease and to explore possible correlations with insulin resistance and related progression of cardiovascular disease in Iraqi men.

Methods: Sixty-three T2DM patients, including forty-two with cardiovascular disease (CVD), were divided into three subgroups; twenty-one with myocardial infraction (MI), twenty-one with other CVD, and twenty-one without any cardiac complication. In addition, a group of twenty-one men served as healthy controls (HCs) for comparison purposes. The four groups were analyzed for parameters that included fasting serum glucose (FSG), lipid profile, fasting serum insulin (FSI), homeostasis model assessment of insulin resistance (HOMA-IR), cardiac Troponin-I (cTn-I), CK-MB, and some other biochemical variables.

Results: Our results showed that the serum CLU levels were higher in T2DM with MI than the other groups of patients, while the levels were significantly elevated in the entire T2DM group as compared to the control group. Serum levels of CLU showed significantly positive correlations with cTn-I and CK-MB ( $r=0.658 \mathrm{p}<$ 0.01 and $\mathrm{r}=0.575, \mathrm{p}<0.01$, respectively), whereas the correlation with HDL-C was negative. However, the other parameters exhibited weak correlations with serum CLU levels.

Conclusions: CLU participates in the event of cardiovascular disease and insulin resistance in Iraqi males with T2DM and may be used as predictor for CVD development in T2DM patients.
\end{abstract}

Keywords: Clusterin, Troponin-I, insulin resistance, Type 2 diabetes mellitus, CVD.

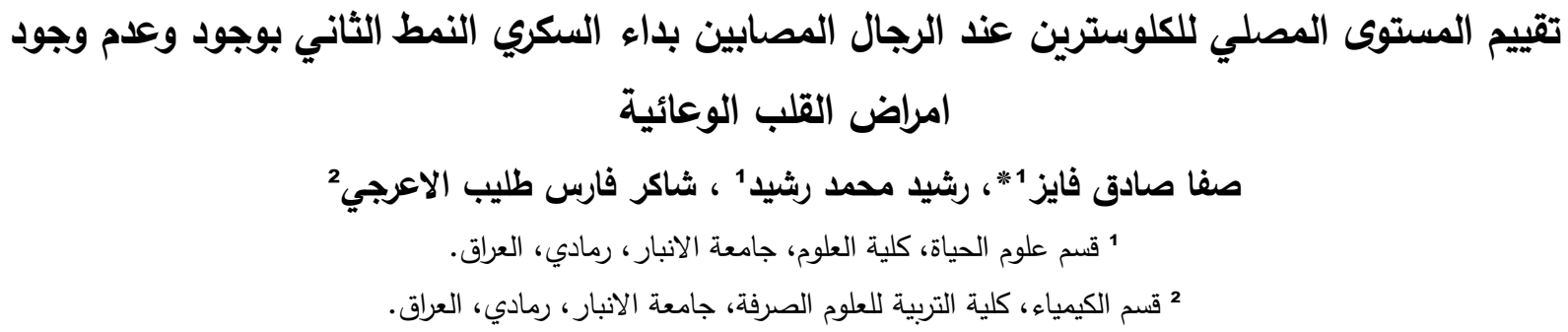

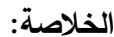

$$
\begin{aligned}
& \text { الاهداف: هدفت الدراسة الحالية الى تقيم المستويات المصلية للكلوسترين في مرضى السكري النمط الثاني } \\
& \text { بوجود وعدم وجود امراض القلب الوعائية عند الرجال العراقيين. بالإضافة الى التحري عن وجود علاقة ارتباط } \\
& \text { بمقاومة الانسولين وتطور امراض القلب الوعائية. }
\end{aligned}
$$

*Email: safaalsadeq@yahoo.com 


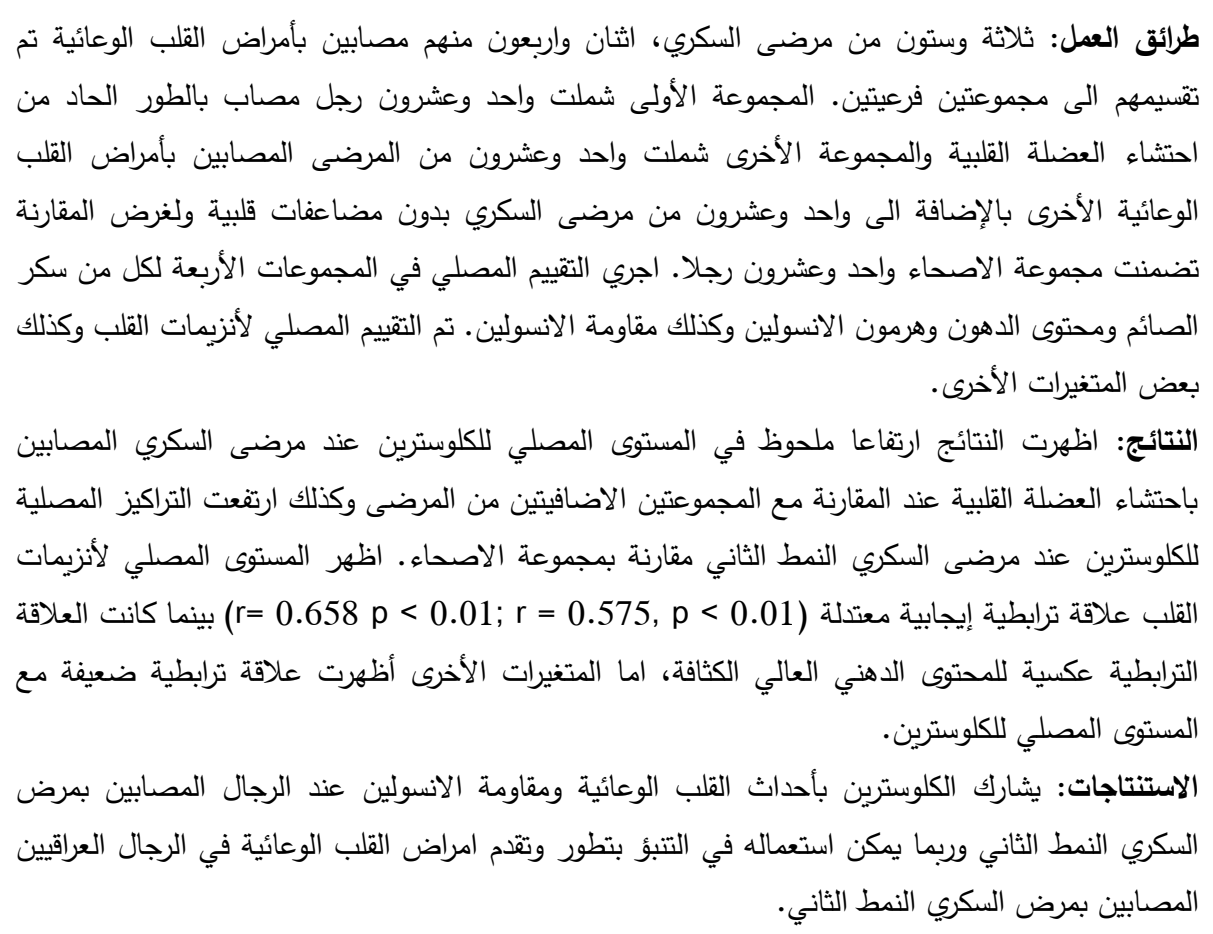

\section{Introduction}

Type 2 diabetes mellitus (T2DM) is a significant global health issue that impacts millions of individuals globally and is linked with severe comorbidities, including CVD and Insulin resistance (IR), coupled with the inability of pancreatic $\beta$-cells to adequately compensate for enhanced insulin secretion[1]. CLU (Apolipoprotein J) is a glycoprotein with many features that were linked with many pathological and physiological conditions, such as Alzheimer's disease (AD), with a distinguished function as an extracellular chaperone. There are also several debated additional roles for CLU, including immune modulation and lipid transport. CLU was also reported to be a participant in many pathways for a number of illnesses, such as oxidative stress, cell death, survival, and proteotoxic stress. Although CLU is normally a secreted protein, it was also discovered intracellularly under certain conditions of stress [2]. CLU gene has three isoforms (Isoform 1, isoform 2, isoform 11036) which, depending on alternative splicing, produce three different proteins which have different localizations and several biological functions. The nuclear clusterin (nCLU) promotes cell death, whereas the secretory clusterin (sCLU) is composed of two subunits $(\alpha$ and $\beta$ ) and has cytoprotective and chaperone roles [3]. Plasma CLU levels are elevated in T2DM , myocardial infarction (MI) and during the development of coronary heart disease [4]. Moreover, CLU levels were shown to increase in patients of prostate cancer [5]. Adipocyte-derived CLU is a new extracellular matrix (ECM) -linked protein that is linked to obesity and cardiometabolic disease through its action in the liver. Levels CLU showed an increase in the adipocytes of obese people [6]. CLU was also recognized as an apolipoprotein-linked protein implicated in the transport of cholesterol and lipids. Additionally, it might have a role in local lipid redistribution [7]. Information on the potential role of CLU in T2DM etiopathogenesis is inconsistent [8]. Therefore, the aim of this study was to serologically assess the involvement of CLU in men with diabetes and CVD or myocardial infarction (MI).

\section{Material and Methods}

Case-control was introduced for comparison in the present study. The study was conducted at the General Educational Hospital in Ramadi from July 2018 to December 2018. Sixty-three patients (Males with an age range of 39- 65 years), previously diagnosed with T2DM based on the norms suggested by the World Health Organization (WHO) were included. Forty-two of the patients were collected from the central care unit (C.C.U) after clinically diagnosed by the consultant physicians to have cardiac problems. Samples were collected after approval from the patients. The ECG findings showed that 21 of the patients had an acute myocardial infarction (AMI). The healthy controls (HCs) group included 21 males who were selected after confirming their safety via laboratory tests and physical examination. All patients relying on insulin injections were excluded [9]. Body mass index 
(BMI) was measured for all subjects by dividing the weight in $\mathrm{kg}$ on height in $\mathrm{m}^{2}$. Also, blood pressure $(\mathrm{mmHg})$ and pulse rate $\left(\mathrm{Min}^{-1}\right)$ were measured by mercury sphygmomanometer.

A blood sample ( $5 \mathrm{~mL}$ ) was gathered after fasting (for 12 hours) from all respondents and left to clot in a plain tube for half an hour in $25{ }^{\circ} \mathrm{C}$. Serum was isolated by centrifugation at $5000 \mathrm{xg}$ for 15 minutes, after which the sera were kept in Eppendorf tubes at $-20^{\circ} \mathrm{C}$ until use. Sera concentrations of FSG and lipid profile were also determined.

Level of cTn-I was determined based on sandwich immunodetection method via ichroma device and the appropriate kit. CK-MB was measured using Fuji dri-chem analyzer, whereas FSI and CLU were determined by enzyme- linked immunosorbent assay (ELISA). The homeostasis model assessment of insulin resistance index (HOMA-IR) was calculated using the equation bellow [10]:

\section{HOMA-IR = insulin (micro units per milliliter $) \times$ glucose $(\mathrm{mg} / \mathrm{dL}) \div 405$}

\section{Statistical Analysis}

All data was analyzed with descriptive statistical analysis using the Statistical Package for the Social Sciences (SPSS) (SPSS Inc., Chicago, IL, USA) software, version 25.0. All studied variables were expressed as mean \pm standard deviation (SD). The significance of differences among the groups was determined by one-way ANOVA test. The correlations between variables were confirmed by Pearson correlation analysis. $P$. values of less than 0.05 were considered to be significant.

\section{Results}

The clinical features of the studied subjects are shown in Table 1. The mean age values (years) of the men in the patient groups, i.e., T2DM, T2DM with MI, and T2DM with other CVD, were 56.24 \pm $9.99,58.00 \pm 9.01$ and $58.60 \pm 11.53$, respectively, while it was $56.05 \pm 6.08$ in the control group. The mean of BMI in T2DM with other CVD group was $\left(28.86 \pm 5.09 \mathrm{~kg} / \mathrm{m}^{2}\right)$, which showed a significant difference with control group $\left(25.60 \pm 4.35 \mathrm{~kg} / \mathrm{m}^{2}\right)$, while the date refers to the non-significant difference at $P<0.05$ between other groups of patients as compared with a control group. The mean values of SBP, DBP and heart rate were found to be higher in the patient groups when compared to the control group. On the other side, serum levels of FSG, FSI, TG, and VLDL-C were significantly greater in male patients than in the control group. Furthermore, the mean value of HOMA-IR was significantly higher in the patients than the control group, as shown in fig.1. Nevertheless, nonsignificant differences were found in the levels of total cholesterol (TC) and low-density lipoprotein (LDL-C) in the studied groups. The date is shown non - significant difference in levels of HDL-C between T2DM group and control group $(40.65 \pm 7.01 \mathrm{mg} / \mathrm{dL})(42.38 \pm 8.63 \mathrm{mg} / \mathrm{dL})$ respectively, the mean of serum HDL-C in T2DM with CVD groups (MI and other CVD) as compared with a control group showed significantly $(P<0.05)$ decrease.

The cTn-I levels were significantly higher in the MI group $(4.3 \pm 0.78 \mathrm{ng} / \mathrm{mL})$ as compared to the other patient groups and control, as shown in table 1 and fig.2. CK-MB levels in the control subjects were non-significantly different to the T2DM group (16.05 \pm 5.82 vs. $14.81 \pm 6.18 \mathrm{IU} / \mathrm{L}$, respectively), while it was significantly different when compared with the other studied groups, reaching a high value in the CVD group but a highest value in the MI group. The mean of serum CLU in control group was $(5.01 \pm 1.27 \mathrm{ng} / \mathrm{mL})$ and was significantly greater in the patient groups, which it reaches peak value in patients with MI $(13.08 \pm 3.72 \mathrm{ng} / \mathrm{mL})$, then the value gradually declines in T2DM with other CVD $(7.59 \pm 1.72 \mathrm{ng} / \mathrm{mL})$ as compared with two other groups of patients (Table 1 and fig.3).

As shown in table 2 (fig.4 and fig.5), the correlation coefficient (r) analysis of cTn-I and CK-MB showed a moderately positive correlation with CLU $(\mathrm{r}=0.658, \mathrm{p}<0.01$ and $\mathrm{r}=0.575, \mathrm{p}<0.01$, respectively). Also, a weakly positive correlation value was found between HOMA-IR and FSI ( $\mathrm{r}=$ $0.435, \mathrm{p}<0.01$ and $\mathrm{r}=0.379, \mathrm{p}<0.01$, respectively). In addition, weakly positive correlations were recorded between CLU and each of the parameters of SBP, DBP, Pulses, TG, TC, LDL-C and VLDL. However, HDL-C in the T2DM group showed a negatively correlation with CLU 
Table 1- Clinical and biochemical properties of subjects studied

\begin{tabular}{|c|c|c|c|c|}
\hline \multirow[b]{2}{*}{ Variables } & \multirow[b]{2}{*}{ Control(N=21) } & \multirow[b]{2}{*}{$\mathrm{T} 2 \mathrm{DM}(\mathrm{N}=21)$} & \multicolumn{2}{|c|}{ T2DM with CVD $(\mathrm{N}=42)$} \\
\hline & & & MI (N=21) & Other CVD $(\mathrm{N}=21)$ \\
\hline Age(y) & $56.05 \pm 6.08^{a}$ & $56.24 \pm 9.99^{\mathrm{a}}$ & $58.00 \pm 9.01^{\mathrm{a}}$ & $58.60 \pm 11.53^{\mathrm{a}}$ \\
\hline BMI $\left(\mathrm{Kg} / \mathrm{m}^{2}\right)$ & $25.60 \pm 4.35^{\mathrm{a}}$ & $27.35 \pm 3.40^{\mathrm{a}}$ & $27.81 \pm 4.74^{\mathrm{a}}$ & $28.86 \pm 5.09^{b}$ \\
\hline SBP (mmHg) & $117.62 \pm 11.36^{\mathrm{a}}$ & $132.10 \pm 20.93^{\mathrm{bd}}$ & $140.95 \pm 12.61^{\mathrm{cd}}$ & $134.76 \pm 6.80^{\mathrm{d}}$ \\
\hline DBP (mmHg) & $70.95 \pm 7.68^{\mathrm{a}}$ & $79.52 \pm 11.17^{b}$ & $88.10 \pm 5.36^{c}$ & $83.24 \pm 5.05^{\mathrm{b}}$ \\
\hline Pulses Min ${ }^{-1}$ & $78.48 \pm 8.27^{\mathrm{a}}$ & $85.57 \pm 10.06^{b}$ & $89.33 \pm 8.14^{b}$ & $83.43 \pm 5.64^{\mathrm{a} b}$ \\
\hline FSG (mg/dL) & $92.24 \pm 11.32^{\mathrm{a}}$ & $218.29 \pm 71.36^{b}$ & $254.29 \pm 47.24^{b}$ & $237.29 \pm 83.09^{b}$ \\
\hline FSI ( $(\mathrm{MIU} / \mathrm{mL})$ & $7.702 \pm 2.586^{\mathrm{a}}$ & $11.57 \pm 2.118^{b}$ & $19.76 \pm 3.455^{\mathrm{c}}$ & $23.81 \pm 4.88^{d}$ \\
\hline HOMA-IR(\%) & $1.37 \pm 0.39^{\mathrm{a}}$ & $4.18 \pm 1.24^{b}$ & $9.70 \pm 3.16^{\mathrm{c}}$ & $8.47 \pm 3.01^{\mathrm{c}}$ \\
\hline $\mathrm{TG} \mathrm{mg} / \mathrm{dL}$ & $101.90 \pm 39.31^{\mathrm{a}}$ & $183.33 \pm 67.49^{b}$ & $196.71 \pm 14.85^{b}$ & $186.19 \pm 62.53^{b}$ \\
\hline $\mathrm{TC} \mathrm{mg} / \mathrm{dL}$ & $176.46 \pm 29.41^{\mathrm{a}}$ & $182.33 \pm 54.35^{\mathrm{a}}$ & $200.89 \pm 37.54^{\mathrm{a}}$ & $184.00 \pm 46.13^{\mathrm{a}}$ \\
\hline HDL-C mg/dL & $42.38 \pm 8.63^{\mathrm{a}}$ & $40.65 \pm 7.01^{\mathrm{a}}$ & $34.77 \pm 6.42^{b}$ & $35.10 \pm 7.77^{b}$ \\
\hline LDL-C mg/dL & $113.70 \pm 29.43^{\mathrm{a}}$ & $105.01 \pm 48.71^{\mathrm{a}}$ & $126.78 \pm 34.83^{\mathrm{a}}$ & $111.20 \pm 42.98^{a}$ \\
\hline VLDL-C mg/dL & $20.38 \pm 7.86^{\mathrm{a}}$ & $36.67 \pm 13.50^{b}$ & $39.34 \pm 2.97^{b}$ & $36.95 \pm 12.76^{\mathrm{b}}$ \\
\hline TN-I (ng/mL) & $0.13 \pm 0.02^{\mathrm{a}}$ & $0.20 \pm 0.03^{\mathrm{a}_{\mathrm{d}}}$ & $4.3 \pm 0.78^{b}$ & $0.40 \pm 0.12^{\mathrm{cd}}$ \\
\hline CK-MB ( IU/L) & $16.05 \pm 5.82^{\mathrm{a}}$ & $14.81 \pm 6.18^{\mathrm{a}}$ & $67.95 \pm 7.54^{b}$ & $25.33 \pm 1.68^{c}$ \\
\hline CLU (ng/mL) & $5.01 \pm 1.27^{\mathrm{a}}$ & $9.53 \pm 2.86^{b}$ & $13.08 \pm 3.72^{c}$ & $7.59 \pm 1.72^{\mathrm{d}}$ \\
\hline
\end{tabular}

Data are represented as Mean \pm SD. BMI: body mass indix ,Sys.BP: systolic blood pressure, Dia.BP: diastolic blood pressure, FSG: fasting serum glucose,FSI: fasting serum insulin ,HOMA-IR: homeostasis model assessment of insulin resistance,TG: triglycerides ,TC: total cholesterol HDL-C: high-density lipoprotein, LDL-C: low-density lipoprotein, VLDL: very low-density lipoprotein. Similar letters: means there is non-significant difference. Different letters: means there is a significant difference.

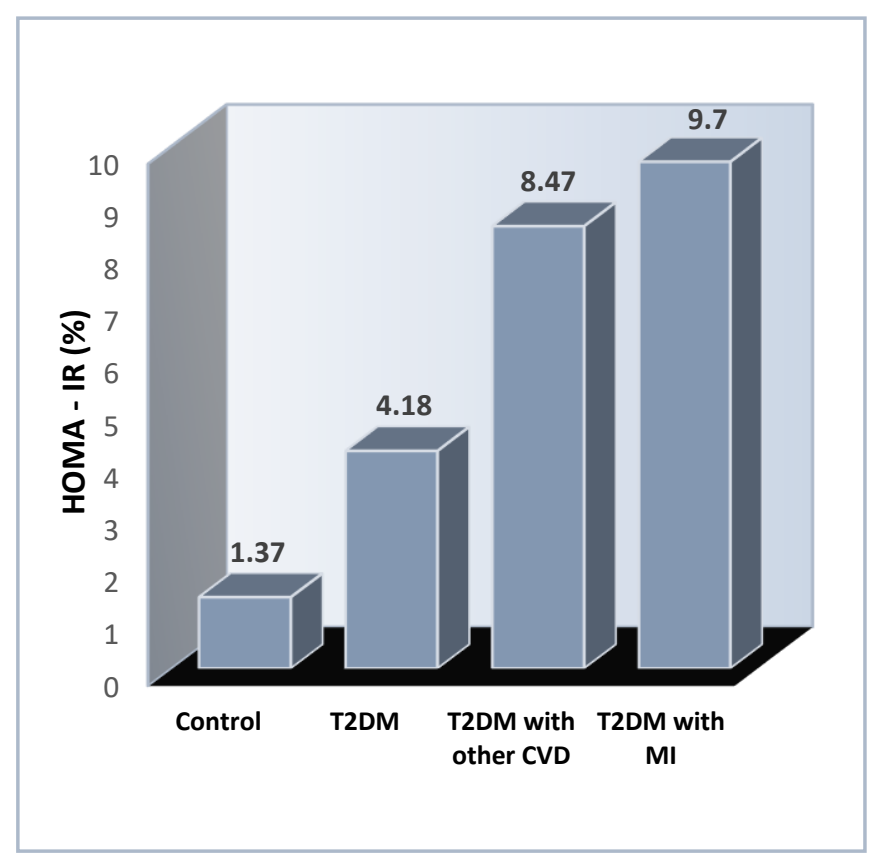

Figure 1- Mean for HOMA-IR in study groups

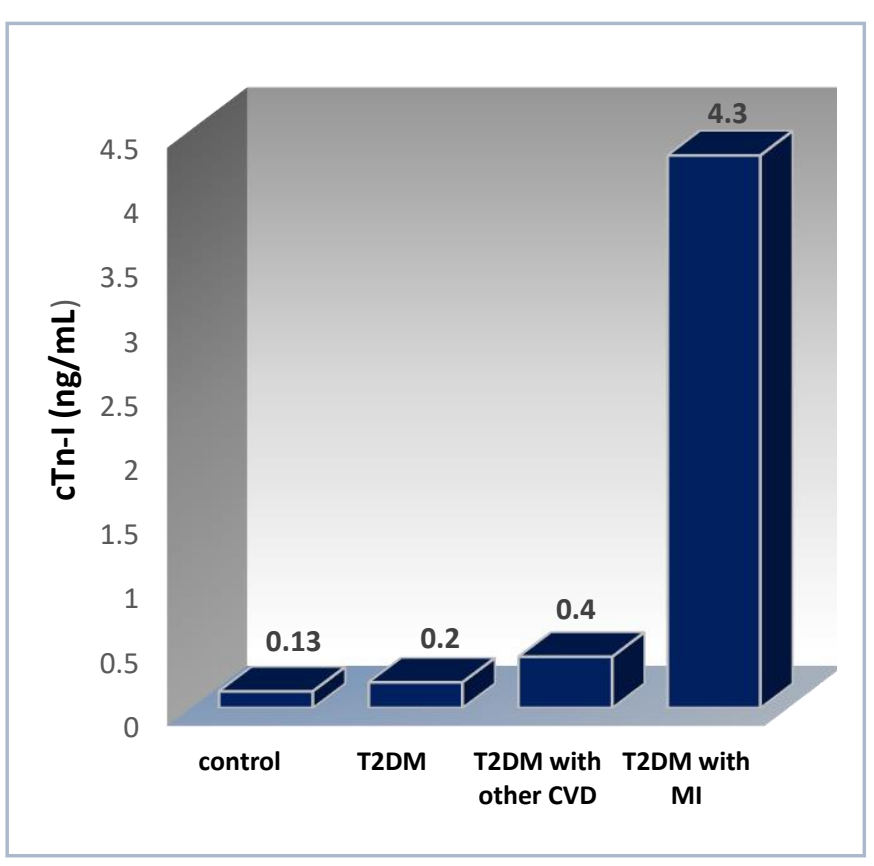

Figure 2- Mean for cTn-I in study groups 
Table 2- Correlation for CLU with biochemical variables

\begin{tabular}{|c|c|c|}
\hline \multirow{2}{*}{ Variables } & \multicolumn{2}{|c|}{ Clusterin (ng/mL) } \\
\cline { 2 - 3 } & 0.039 & $P$. Value \\
\hline Age(y) & 0.072 & - \\
\hline BMI $\left(\mathrm{Kg} / \mathrm{m}^{2}\right)$ & 0.309 & $<0.01$ \\
\hline SBP $(\mathrm{mmHg})$ & 0.440 & $<0.01$ \\
\hline DBP $(\mathrm{mmHg})$ & 0.361 & $<0.01$ \\
\hline Pulses Min ${ }^{-1}$ & 0.39 & $<0.01$ \\
\hline F.S.G $(\mathrm{mg} / \mathrm{d} \mathrm{L})$ & 0.379 & $<0.01$ \\
\hline F.S.I $(\mathrm{MIU} / \mathrm{mL})$ & 0.435 & $<0.01$ \\
\hline HOMA-IR(\%) & 0.335 & $<0.01$ \\
\hline T.G $\mathrm{mg} / \mathrm{dL}$ & 0.106 & - \\
\hline T. C mg/dL & -0.196 & - \\
\hline HDL. C mg/dL & 0.051 & $<0.01$ \\
\hline LDL-C mg/dL & 0.344 & $<0.01$ \\
\hline VLDL mg/dL & 0.658 & $<0.01$ \\
\hline TN-I $(\mathrm{ng} / \mathrm{mL})$ & 0.575 & \\
\hline CK-MB $(\mathrm{IU} / \mathrm{L})$ & & \\
\hline
\end{tabular}

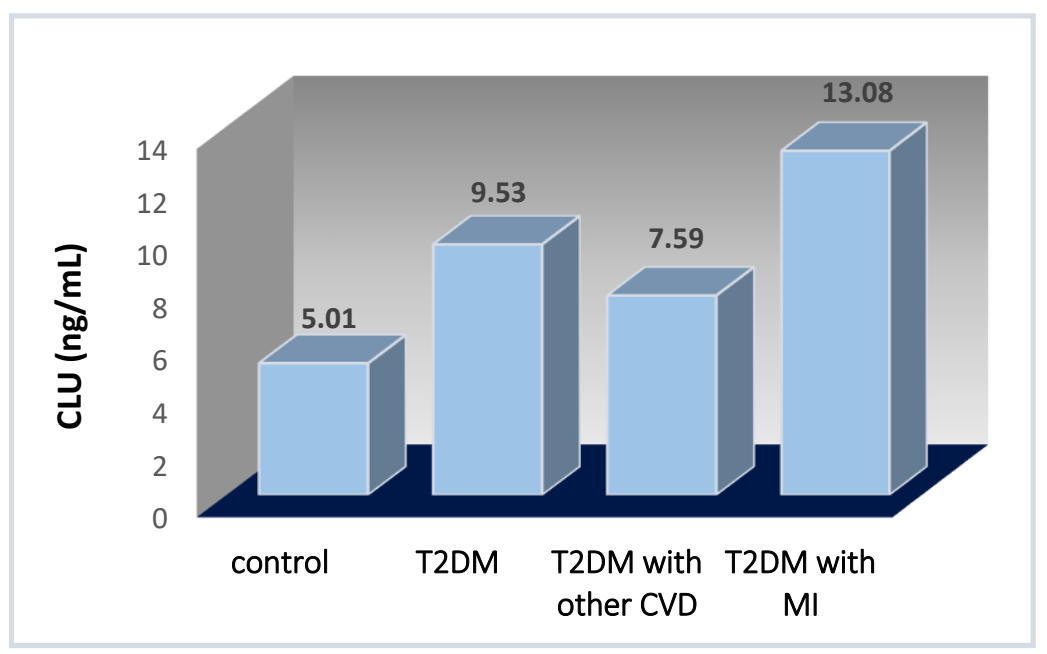

Figure 3- Mean for CLU in study groups
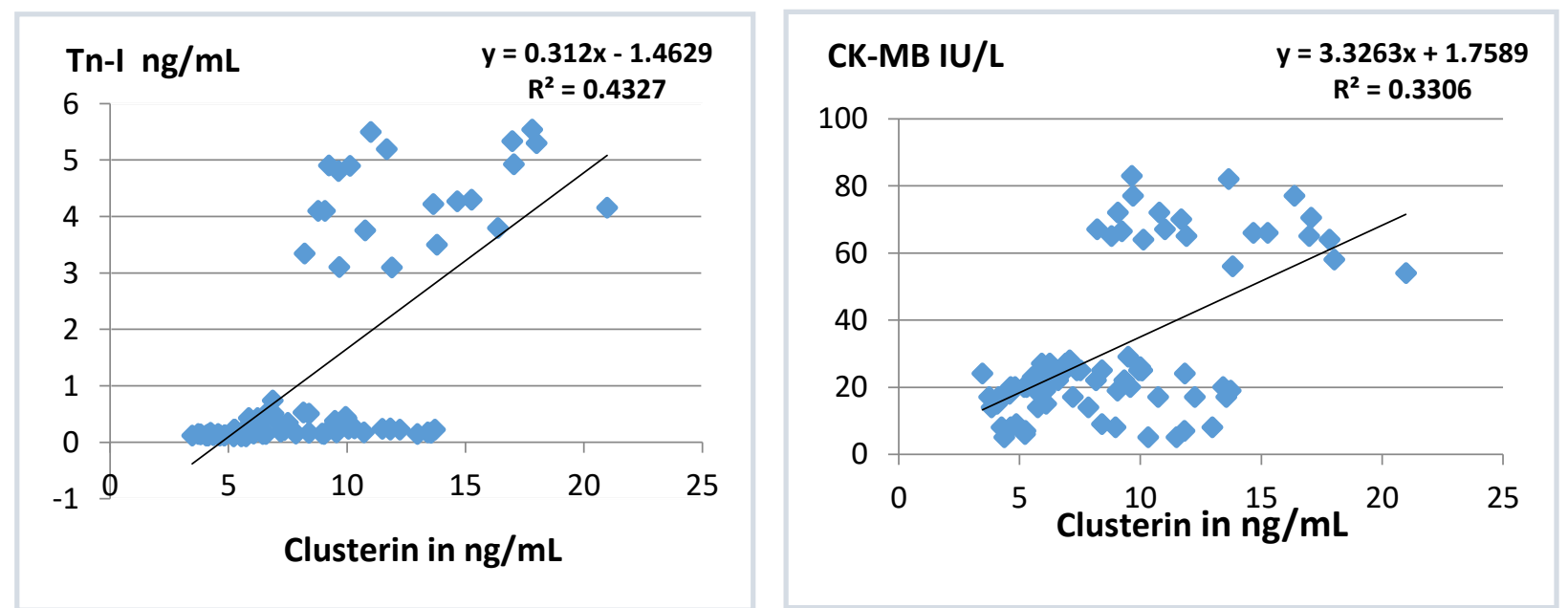

Figure 4- Correlation of CLU with Tn-I in T2DM

Figure 5- Correlation of CLU with CK-MB in T2DM

\section{Discussion}

The CLU content in lipoproteins is changed in patients with CVD risk, including those with insulin resistance, dyslipidemia, and obesity. It was shown that a lower CLU content in HDL-C might impair its anti-apoptotic function in CVD patients [11]. Serum CLU levels were also shown to be elevated in 
patients with T2DM, which is a well-defined risk factor for atherosclerosis [12,13]. In addition, a greater number of metabolic syndrome elements are associated with greater plasma CLU levels. Also, the metabolic syndrome is more common in males than in females, which may contribute to elevating circulating CLU levels in males [14]. The present results demonstrated that serum CLU level is increased in T2DM and CVD patients and reaches its peak value in the MI subgroup (9.53 $\pm 2.86,7.59$ \pm 1.72 and $13.08 \pm 3.72$, respectively). Immunostaining analysis of CLU in patients who died of MI demonstrated that CLU is not deposited in healthy tissues but in damaged myocardial myocytes [15]. Thus, CLU is linked to vascular damage as a potential promoter of strong stress signals that result in its secretion and production by many epithelia which are distant to the site of injury [4]. Accumulation of CLU in the coronary artery wall during the development of atherosclerosis is followed by a rise in CLU serum levels [16]. The function of CLU in the heart appears to be more simple and it is deemed mainly protective in cardiac cells during disease and damage. The evidence suggests that CLU role in the heart may be attributed to its role in the transporter of lipids [2]. Furthermore, CLU overexpression during the damage of blood vessels by adenovirus prevents adhesion, proliferation, and migration of vascular smooth muscle cells and exerts protective roles on endothelial cells [17]. Whether increased CLU levels have beneficial or adverse effects on the cardiovascular system is still inconclusive [14]. There is a hypothesis that CLU in atherosclerotic- plaques may be derived from a protein that circulates in the plasma, or maybe partly produced from depositions in the plateletgranules and released into extracellular fluid after platelet activation [4]. Seo et al showed that fasting serum CLU greatly elevated by $\sim 50 \%$, in T2DM patient compared to non-diabetic subjects [1]. The elevation of CLU level in diabetic possibly a result of the increased transmission of oxidized lipids in the liver [9]. In a study conducted on the Japanese population, it was demonstrated that the CLU gene polymorphism rs2279590 was associated with T2DM through increment of insulin resistance and reduction of insulin secretion [18]. Insulin resistance and obesity lead to changes in the content of lipids and the structure of lipoproteins, which may affect the distribution of CLU among distinct classes of lipoprotein particles. Therefore, this finding raises the possibility of direct correlation of CLU in insulin resistance, LDL-C, and VLDL-C. This correlation increases the potential that insulin resistance might lead to the transfer of proteins from HDL-C to LDL-C and VLDL-C. Also, another study showed that CLU in HDL is correlated negatively with TG, T.C, and LDL-C and positively with HDL-C [19]. Our results on diabetic patients are in agreement with those of Seo et al and Kujiraoka et al $[1,9]$. Our findings also demonstrated a positive correlation between CLU and insulin resistance, possibly due to the notion that CLU levels are associated with the magnitude of insulin resistance in diabetic or non-diabetic conditions [1]. The present study was restricted to males. The previous studies revealed that CLU accumulates in the aorta of males with advancing in age [20]. CLU may have a protective role but, changes in lipid metabolism in T2DM patients may affect the content of the CLU in lipoprotein and, therefore, reduce the HDL -CLU content. In conclusion, serum clusterin may participate in the events of insulin resistance and cardiovascular disease in type 2 diabetic patients. Also, CLU may be used as a novel predictor for the diagnosis of cardiac complications in type 2 diabetic patients.

\section{References}

1. Seo, J.A., Kang, M.C., Ciaraldi, T.P., Kim, S.S., Park, K.S., Choe, C., Hwang, W.M., Lim, D.M., Farr, O., Mantzoros, C. and Henry, R.R . 2018. Circulating ApoJ is closely associated with insulin resistance in human subjects. Metabolism, 78: 155-166.

2. Foster, E., Dangla Valls, A., Lovestone, S., Ribe, E.M. and Buckley, N.J. 2019. Clusterin in Alzheimer's disease: mechanisms, genetics, and lessons from other pathologies. Frontiers in neuroscience, 13: 164.

3. Koltai, T. 2014. Clusterin: a key player in cancer chemoresistance and its inhibition. OncoTargets and therapy, 7: 447.

4. Trougakos, I.P., Poulakou, M., Stathatos, M., Chalikia, A., Melidonis, A. and Gonos, E.S. 2002. Serum levels of the senescence biomarker clusterin/apolipoprotein $\mathbf{J}$ increase significantly in diabetes type II and during development of coronary heart disease or at myocardial infarction. Experimental gerontology, 37(10-11): 1175-1187.

5. Miyake, H., Muramaki, M., Furukawa, J., Kurahashi, T. and Fujisawa, M. 2010. Serum level of clusterin and its density in men with prostate cancer as novel biomarkers reflecting disease extension. Urology, 75(2): 454-459. 
6. Bradley, D., Blaszczak, A., Yin, Z., Liu, J., Joseph, J.J., Wright, V., Anandani, K., Needleman, B., Noria, S., Renton, D. and Yearsley, M. 2019. Clusterin Impairs Hepatic Insulin Sensitivity and Adipocyte Clusterin Associates With Cardiometabolic Risk. Diabetes care, 42(3): 466-475.

7. Jenne, D.E., Lowin, B., Peitsch, M.C., Böttcher, A., Schmitz, G. and Tschopp, J. 1991. Clusterin (complement lysis inhibitor) forms a high density lipoprotein complex with apolipoprotein AI in human plasma. Journal of Biological Chemistry, 266(17): 11030-11036.

8. Kloučková, J., Lacinová, Z., Kaválková, P., Trachta, P., KASALICK3Ý, M., Haluzíková, D., Mráz, M. and Haluzík, M. 2016. Plasma concentrations and subcutaneous adipose tissue mRNA expression of clusterin in obesity and type 2 diabetes mellitus: the effect of short-term hyperinsulinemia, very-low-calorie diet and bariatric surgery. Physiological research, 65(3).

9. Kujiraoka, T., Hattori, H., Miwa, Y., Ishihara, M., Ueno, T., Ishii, J., Tsuji, M., Iwasaki, T., Sasaguri, Y., Fujioka, T. and Saito, S. 2006. Serum apolipoprotein j in health, coronary heart disease and type 2 diabetes mellitus. Journal of atherosclerosis and thrombosis, 13(6): 314-322.

10. Matthews, D.R., Hosker, J.P., Rudenski, A.S., Naylor, B.A., Treacher, D.F. and Turner, R.C. 1985. Homeostasis model assessment: insulin resistance and $\beta$-cell function from fasting plasma glucose and insulin concentrations in man. Diabetologia, 28(7): 412-419.

11. Rull, A., Martínez-Bujidos, M., Pérez-Cuellar, M., Pérez, A., Ordóñez-Llanos, J. and SánchezQuesada, J.L. 2015. Increased concentration of clusterin/apolipoprotein J (apoJ) in hyperlipemic serum is paradoxically associated with decreased apoJ content in lipoproteins. Atherosclerosis, 241(2): 463-470.

12. Tegos, T.J., Kalodiki, E., Sabetai, M.M. and Nicolaides, A.N. 2001. The genesis of atherosclerosis and risk factors: a review. Angiology, 52(2): 89-98.

13. Holm, P., Korsgaard, N., Shalmi, M., Andersen, H.L., Hougaard, P., Skouby, S.O. and Stender, S.1997. Significant reduction of the antiatherogenic effect of estrogen by long-term inhibition of nitric oxide synthesis in cholesterol-clamped rabbits. The Journal of clinical investigation, 100(4): 821-828.

14. Won, J.C., Park, C.Y., Oh, S.W., Lee, E.S., Youn, B.S. and Kim, M.S. 2014. Plasma clusterin (ApoJ) levels are associated with adiposity and systemic inflammation. PloS one, 9(7): p.e103351.

15. Väkevä, A., Laurila, P. and Meri, S. 1993. Co-deposition of clusterin with the complement membrane attack complex in myocardial infarction. Immunology, 80(2): 177.

16. Poulakou, M.V., Paraskevas, K.I., Vlachos, I.S., Karabina, S.A.P., Wilson, M.R., Iliopoulos, D.C., Tsitsilonis, S.I., Mikhailidis, D.P. and Perrea, D.N. 2008. Effect of statins on serum apolipoprotein $\mathrm{j}$ and paraoxonase-1 levels in patients with ischemic heart disease undergoing coronary angiography. Angiology, 59(2):137-144.

17. Kim, H.J., Yoo, E.K., Kim, J.Y., Choi, Y.K., Lee, H.J., Kim, J.K., Jeoung, N.H., Lee, K.U., Park, I.S., Min, B.H. and Park, K.G. 2009. Protective role of clusterin/apolipoprotein J against neointimal hyperplasia via antiproliferative effect on vascular smooth muscle cells and cytoprotective effect on endothelial cells. Arteriosclerosis, thrombosis, and vascular biology, 29(10): 1558-1564.

18. Daimon, M., Oizumi, T., Karasawa, S., Kaino, W., Takase, K., Tada, K., Jimbu, Y., Wada, K., Kameda, W., Susa, S. and Muramatsu, M. 2011. Association of the clusterin gene polymorphisms with type 2 diabetes mellitus. Metabolism, 60(6): 815-822.

19. Hoofnagle, A.N., Wu, M., Gosmanova, A.K., Becker, J.O., Wijsman, E.M., Brunzell, J.D., Kahn, S.E., Knopp, R.H., Lyons, T.J. and Heinecke, J.W. 2010. Low clusterin levels in high-density lipoprotein associate with insulin resistance, obesity, and dyslipoproteinemia. Arteriosclerosis, thrombosis, and vascular biology, 30(12): 2528-2534.

20. Ishikawa, Y., Ishii, T., Akasaka, Y., Masuda, T., Strong, J.P., Zieske, A.W., Takei, H., Malcom, G.T., Taniyama, M., Choi-Miura, N.H. and Tomita, M. 2001. Immunolocalization of apolipoproteins in aortic atherosclerosis in American youths and young adults: findings from the PDAY study. Atherosclerosis, 158(1): 215-225. 